\title{
Implementation Strategies of Low-Carbon Tourism
}

\author{
Yingfa Yang* \\ Division of Social Sciences, Hebei Engineering University, Handan, 056001, Hebei, China
}

\begin{abstract}
Currently, low-carbon lifestyle has come to the fore, and is valued by the countries around the world. Accordingly, low-carbon tourism has become the goal of development. It is a long way to go, but we have aimed high in the ongoing exploration. This paper is to provide a reference for the construction of low-carbon tourism. It is unfolded with the definition and importance of low-carbon tourism, followed by basic evaluation system of low-carbon tourism and specific suggestions for its implementation.
\end{abstract}

Keywords: Evaluation system, implementation strategy, low carbon tourism.

\section{INTRODUCTION}

Under the aggregation of world energy crisis, low-carbon lifestyle has been valued all over the world. In the Specific Suggestions of Tourism Development proposed by the State Council in 2009, it is mentioned that the course for the future of tourism industry is low-carbon tourism [1-4], which requires joint efforts from the government, tourism sector, and faculty of research, so that tourism can develop in an efficient, energy saving, and eco-friendly way.

\section{BASIC THEORY OF LOW-CARBON TOURISM}

\subsection{Definition of Low-Carbon Tourism}

The so called low-carbon tourism as the name suggests is to reduce "carbon" emissions during travel. The "carbon" here means green house gases, carbon dioxide mainly. In other words, it should be green travel [5-8], with light energy consumption, little pollution, and few carbon dioxide emissions. Low-carbon tourism is designed with low-carbon itineraries, equipped with eco-friendly outfit, and required low transport emissions.

\subsection{Connotation of Low-Carbon Tourism}

\subsubsection{Content of Low-Carbon Tourism}

Low-carbon tourism is an extension of low-carbon economy. It is in the framework of low-carbon economy. Supported by low-carbon technology and low-carbon mechanism, low-carbon tourism aims at reducing the carbon dioxide emission and the consumption of energy during travel [9, 10 ], so that both the needs of wonderful traveling experience and sustainable development of economy and environment can be met.

\subsubsection{The Meaning of Low-Carbon Tourism}

Essentially low-carbon tourism is an extension of ecotourism. It requires low-carbon production and operation in the tourism. For example, with the help of new technology and new energy sources, hotels, restaurants, scenic spots and transportation reduce water, electricity, and other energy consumption as well as the waste, and ultimately to achieve reduction of greenhouse gas emissions such as carbon dioxide, so that tourism industry and tourism economy can develop along with a sustainable environment. The main requirements of low-carbon tourism are low carbon transportation, low-carbon consumption, low-carbon accommodation and less travel footprints, etc.

\subsection{Significance of Low-Carbon Tourism}

China now faces serious environmental pollution, mainly marked by smog. When tourists are enjoying the scenery in a trip, they should think about whether their activities destroy the land, river, plants, and ecosystem. Here we introduce the significance of low-carbon tourism. The two significance of low-carbon tourism are respectively for individual and society. For individual, modern lifestyle casts great pressure on individuals. Low-carbon tourism is a relaxing travel mode close to nature. Tourists are free from their daily worries and stresses, for example, by walking instead of taking a ride, tourists can enjoy the missing scenery in cars or buses. For society as a whole, low-carbon and environmental protection are urgent. Today, air pollution, energy crisis and other issues cannot be resolved merely through technology and science, but joint efforts from all mankind. Developing lowcarbon lifestyle, however, is the most efficient way to solve the environmental problems brought by economic growth. Tourism is closely related to natural resources, thus it is urgent to make it low-carbon. China is gradually confirmed as one of the world's great powers, it needs to make an example of a large country in the field of environmental protection. Thus the implementation of low-carbon tourism is a necessary measure.

\subsection{Challenges in Implementing Low-Carbon Tourism}

\subsubsection{Terrible Waste of Resources}

Chinese tourism industry is facing appalling waste in its widely existed extensive operation and management. For 
example, energy saving materials are uncommon in the construction of scenic facilities; some construction area is too large; the problem of construction material waste is serious; tourists use times of natural resources than the residents, such as water, electricity, oil and gas; consumable stuff is widely used, for example, disposable toothbrush, slippers, bowl and chopsticks and other items, which causes huge waste and pollution.

\subsubsection{Lack of Environmental Protection Awareness}

According to the survey, Chinese tourists are lack of environmental protection awareness and actions mainly in three aspects: food, shelter, and transportation. First of all, when tourists purchasing the specialty or special food, they always select those with delicate packages, which increases the emissions in packaging, storage, and transporting. In addition, because of face and vanity, tourists choose large luxurious restaurants and causes great waste. Secondly, tourists often use disposable supplies provided by the hotel, resulting in waste. Finally, people travel with fast and convenient transportation such as airplane. In addition, with the increase in private car ownership, driving becomes one of the main means of traveling. While people are enjoying the convenience of transportation, they are placing the environment at heavy greenhouse gas emission.

\subsubsection{Damage to the Environment of Tourism Resources Exploitation}

In developing tourism economy, exploiting tourism resources plays an important role. However, the course of exploiting tourism resources in the pursuit of economic growth also damages environment. Many scenic interests have explored and exploited natural resources without cautious inspection, demonstration and scientific planning, but simply pursued economic growth. Such activity sacrifices natural resources, and damages local ecology and environment.

\section{EVALUATE THE BASIC MODEL OF LOW- CARBON TRAVEL}

\subsection{Basic Principles of the System Construction}

\subsubsection{Comprehensive Representation Principle}

The standard in the table is an organic whole. It comprehensively reflects economic results from low-carbon tourism. From each different perspective, there are different indicators of low-carbon tourism. And only in this way, this model makes sense. What's more, each indicator in the model are mutually independent and representative.

\subsubsection{Principle of Combining Qualitative and Quantitative Evaluation}

The indicators must be selected in the combination of qualitative and quantitative evaluation, so that they are valid and practical. Quantitative principle ensures the evaluation objective and reasonable, while qualitative principle solves problems that are wide-range and cannot be quantified.

\subsubsection{Dynamic Stability Principle}

Developing low-carbon tourism is a dynamic process. Firstly, in the evaluation process, dynamics such as the eco- nomic, technological, and social changes of the indicators must be paid attention. Secondly, the dynamics of the index should be strengthened. In addition, the evaluation system should be relatively stable. This will not only reflect the current situation of eco-tourism but also reflect the perspective of future development.

\subsubsection{Principle of Scientific Use}

The selection of qualitative changes is based on reality, for example, the power of eco-tourism, status, and screenings and other negative understanding and analysis. The indicators should meet the development objective and requirements of eco-tourism, and be reflected in the real economic development, environment protection and legislation.

\subsubsection{Principle of Operation}

In the evaluation system of low-carbon tourism system, we try to use existing data. Despite the inadequate system and indicators of low-carbon tourism, there are still statistics that can be used, and we can rule out those that can't be quantified.

\subsubsection{Principle of System Level}

Low-carbon tourism is a complex systemic issue, whose evaluation system needs to reflect all aspects of the design as well as the characteristics. The system can be divided into macro and micro according to the function.

\subsection{Indicator Framework}

Indicator system is divided into four layers in the following chart: the overall goal, the criteria layer, sub-criteria layer, and the index layer Table 1.

\subsection{Index Weight}

\subsubsection{Matrix}

The first step of analyzing the system is to determine the importance of each layer. Plus $\mathrm{Q}_{\mathrm{k}}$ and the dominance relation with the index in the layer, we can introduce the following matrix, Table 2, to compare which indicator is more important, in which $\mathrm{R}_{\mathrm{j}}>0$.

Now we need to judge if the standard of quality in the matrix is consistent with its result. If it is, we take it a consistent matrix. Because of its complexity of the issue, there are many factors to influence the result, which requires us to use matrix as auxiliary. The R-rated pairwise comparison of each factor can be drawn judgment in the matrix, it is solved as following formula.

\subsubsection{Testing the Consistency of the Matrix}

We can use root method to calculate the maximum in matrix and eigenvectors and normalize them. To calculate the consistency of all levels of arrangement, we can use the following formula:

$$
C R=\frac{C I}{R I}
$$

CI represents a hierarchy consistency, CIj represents the consistency of sub-criteria layer and the corresponding 
Table 1. Index in indicator system at all level.

\begin{tabular}{|c|c|c|c|}
\hline Overall Goal & Criteria & Sub-Criteria & Index \\
\hline \multirow{27}{*}{$\begin{array}{l}\text { Degree of development of } \\
\text { low-carbon tourism }(\mathrm{P})\end{array}$} & \multirow{6}{*}{ Driving force $/ \mathrm{Q}_{1}$} & \multirow{2}{*}{$\begin{array}{c}\text { Comprehensive economic } \\
\text { efficiency } / \mathrm{R}_{1}\end{array}$} & Proportion in GDP/ $\mathrm{S}_{1}$ \\
\hline & & & Revenue growth $/ \mathrm{S}_{2}$ \\
\hline & & \multirow{2}{*}{ Value of tourism resources $/ \mathrm{R}_{2}$} & Number of $4 \mathrm{R}$ level scenic spots/S $\mathrm{S}_{3}$ \\
\hline & & & Resource abundance $/ \mathrm{S}_{4}$ \\
\hline & & \multirow{2}{*}{ Technological advances $/ \mathrm{R}_{3}$} & Proportion of funds in low-carbon technologies $/ \mathrm{S}_{5}$ \\
\hline & & & Ratio of ecological building $/ \mathrm{S}_{6}$ \\
\hline & \multirow{14}{*}{ Ecological indicators $/ \mathrm{Q}_{2}$} & \multirow{3}{*}{ Infrastructure $/ \mathrm{R}_{4}$} & Number of eco-friendly restaurant $/ \mathrm{S}_{7}$ \\
\hline & & & Number of green travel tourists $/ \mathrm{S}_{8}$ \\
\hline & & & Number of buses/ $\mathrm{S}_{9}$ \\
\hline & & \multirow{6}{*}{ Energy emissions $/ \mathrm{R}_{5}$} & Proportion of non-fossil energy sources $/ \mathrm{S}_{10}$ \\
\hline & & & Energy consumption per unit/ $\mathrm{S}_{11}$ \\
\hline & & & Per capita carbon dioxide emissions $/ \mathrm{S}_{12}$ \\
\hline & & & Per capita footprint $/ \mathrm{S}_{13}$ \\
\hline & & & Rise of carbon dioxide emissions $/ \mathrm{S}_{14}$ \\
\hline & & & Emissions from star hotel $/ \mathrm{S}_{15}$ \\
\hline & & \multirow{5}{*}{ Environment $/ \mathrm{R}_{6}$} & Forest coverage $/ \mathrm{S}_{16}$ \\
\hline & & & Urban greening $/ \mathrm{S}_{17}$ \\
\hline & & & Amount of municipal solid waste $/ \mathrm{S}_{18}$ \\
\hline & & & Sewage treatment capacity $/ \mathrm{S}_{19}$ \\
\hline & & & Air pollution treatment capacity $/ \mathrm{S}_{20}$ \\
\hline & \multirow{7}{*}{$\begin{array}{l}\text { Corresponding indica- } \\
\text { tors } / \mathrm{Q}_{3}\end{array}$} & \multirow{2}{*}{ Destination $/ \mathrm{R}_{7}$} & Eco tourism itinerary $/ \mathrm{S}_{21}$ \\
\hline & & & Environmental compliance rate $/ \mathrm{S}_{22}$ \\
\hline & & \multirow{3}{*}{ Administrative department $/ \mathrm{R}_{8}$} & Tourism development plan $/ \mathrm{S}_{23}$ \\
\hline & & & Evaluation system $/ \mathrm{S}_{24}$ \\
\hline & & & Legislation $/ \mathrm{S}_{25}$ \\
\hline & & \multirow{2}{*}{ Tourists $/ \mathrm{R}_{9}$} & Public awareness rate $/ \mathrm{S}_{26}$ \\
\hline & & & Public support rate/ $\mathrm{S}_{27}$ \\
\hline
\end{tabular}

Table 2. $Q_{k}$ matrix.

\begin{tabular}{|c|c|c|c|c|}
\hline $\mathbf{Q}_{\mathbf{k}}$ & $\mathbf{R}_{\mathbf{1}}$ & $\mathbf{R}_{\mathbf{2}}$ & $\ldots$ & $\mathbf{R}_{\mathbf{n}}$ \\
\hline \hline 1 & $\mathrm{R}_{11}$ & $\mathrm{R}_{21}$ & $\ldots$ & $\mathrm{R}_{1 \mathrm{n}}$ \\
\hline $\mathrm{R}_{1}$ & $\mathrm{R}_{12}$ & $\mathrm{R}_{22}$ & $\ldots$ \\
\hline$\ldots$ & $\ldots$ & & $\ldots$ & $\mathrm{R}_{2 \mathrm{n}}$ \\
\hline $\mathrm{R}_{\mathrm{n}}$ & $\mathrm{R}_{13}$ & $\mathrm{R}_{23}$ & $\ldots$ \\
\hline
\end{tabular}




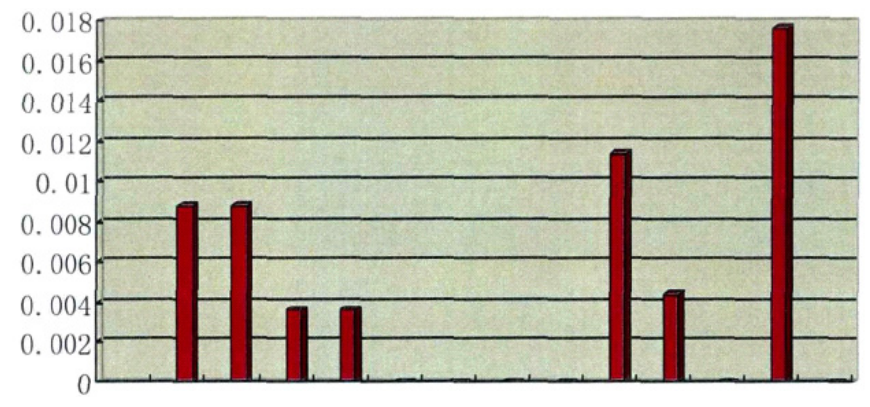

Fig. (1). CR value table.

criteria layer,RI represents random consistency, $R I j$ represents the consistency of sub-criteria layer and the corresponding criteria layer in matrix, $C R$ represents the matrix consistency.

CR values of matrix is shown in Fig. (1).

When $\mathrm{CR}<0.1$, the consistency is regarded to meet the requirement of consistency, otherwise, it does not meet the requirement. According to calculations, the low-carbon tourism matrix meet the requirements of consistency.

\subsubsection{Establishing a Low-Carbon Eco-Tourism Evaluation Model}

The index of low-carbon eco-tourism are of two types, forward index and reverse index, calculated as.

Forward index: $\mathrm{I} i=$ (actual index value $\mathrm{Pi} /$ reference value Ti) $\mathrm{x} 100$

Reverse index: $I i=$ (reference value $T i /$ actual index value Pi) x 100\%

The ecology gathers each individual index in the system and undertakes a comprehensive evaluation. Through a weighting function, it is calculated as

$$
A=\sum_{i=1}^{n}\left(I_{j} \times R_{j}\right) \times W_{j}
$$

\section{MAIN MEASURES TO IMPLEMENT LOW- CARBON TOURISM}

\subsection{Strengthening the Mechanism}

The government and department of tourism strengthen the role of guiding the tourism industry by establishing appropriate systems and build a low-carbon travel system as well as oversight mechanism as auxiliary, for example, manufacturing tourism products, designing itinerary, promoting the significance of low-carbon tourism, and introduce rules and laws. On one hand, the administrative departments should strengthen the low-carbon assessment of the attractions, hotels, restaurants and transportation. With appropriate assessment indicators and restrictions of the energy utilization and emission, the institutes and programs with highvolume emission, heavy pollution, and serious waste will gradually be phased out. On the other hand, incentive mechanism should also be established, to encourage the application of eco-friendly equipment in institutions and other environmental protection behaviors. In addition, government should increase the financial subsidies for low-carbon tour- ism, and introduces conducive tax policy for low-carbon tourism. The United States, for example, is attaching great importance to low-carbon tourism, and have introduced a set of laws and regulations to guide the tourism industry and results have been achieved.

\subsection{Strengthening Plans for Low-Carbon Tourism}

Low-carbon tourism should be placed into the criterion of tourism development, with indicators of carbon dioxide emissions, waste disposal capacity, public transport. When rating hotels and scenic spots, carbon emission should also be one of the criterion. The scenic spot planning must be technically innovative, for example, establishing the evaluation system of "low-carbon scenic spot", and supervising the transport, accommodation, entertainment, manufacture, and distribution sectors. It can be given visual logo of to represent their carbon degree, and the logo should include numbers, graphics, and color, so as to complete the digital network system.

\subsection{Promoting Publication of the Low-Carbon}

Tourists are the principle part of a trip. Take effective measures in a trip is the key to implement low-carbon tourism. With social development, the requirements of environmental protection become increasingly strict, and yet people's awareness does not meet the strict requirements. Thus we should promote publication of the low-carbon awareness. The tourism department is required to take various forms to promote publication deepening into the community, so that residents will raise the awareness of environmental protection, and abandoning the extravagant attitude as well as lifestyle. In the meantime, tourists abandon the behaviors of damaging environment, for example, it is advocated to choose transport with less carbon dioxide emission such as walking, bicycle, bus and train, and lodging into hotels with green logo. Japan performs best in this aspect. The government and social groups regularly advocate in $\mathrm{TV}$, internet and newspaper, so that people are highly aware of lowcarbon and eco-friendly tourism and environmental protection as well.

\section{CONCLUSION}

With increasingly environmental damage brought by growing economy, many cities in China are facing serious environmental pollution such as heavy smog. Thus, lowcarbon environment has become a pressing issue. Tourism as a closely related industry to natural resources, the implementation of low-carbon tourism is essential for the protection of environmental resources. This paper have described the definition of low-carbon tourism, low-carbon tourism evaluation system, as well as collective measures to implement lowcarbon tourism, that is, to strengthen mechanism and plan of low-carbon tourism, and to promote publication of lowcarbon awareness. This study hopes to provide a valuable reference to relevant institutions and staff.

\section{CONFLICT OF INTEREST}

The author confirms that this article content has no conflict of interest. 


\section{ACKNOWLEDGEMENTS}

This work is supported by Hebei Province Social Science Fund "Introverted perspective to the path of Chinese culture promoted the hebei cultural soft power" achievements (No. HB14ZX011).

\section{REFERENCES}

[1] W. Yang, "The development of tourism in the low carbon economy," International Business Research, vol. 3, no. 4, pp. 212, 2010.

[2] Y. Xie, and Z. Yuan, "A study on progress of domestic and overseas low-carbon tourism and its enlightment", Human Geography, vol. 5, pp. 27-31, 2010.

[3] J. Xu, L. Yao, and L. Mo, "Simulation of low-carbon tourism in world natural and cultural heritage areas: An application to Shizhong District of Leshan City in China," Energy Policy, vol. 39, no. 7, pp. 4298-4307, 2011.

[4] Q. Ming, Y. Chen, and Q. Li, "Low-carbon tourism: the strategic choice of the tourism industrial ecology," Human Geography, vol. 5, pp. 22-26, 2010.
[5] G. Wood, "Modelling the ecological footprint of green travel plans using GIS and network analysis: from metaphor to management tool?," Environment and Planning B, vol. 30, no. 4, pp. 523-540, 2003.

[6] J. Liu, T. Feng, and X. Yang, "The energy requirements and carbon dioxide emissions of tourism industry of Western China: A case of Chengdu city," Renewable and Sustainable Energy Reviews, vol. 15, no. 6, pp. 2887-2894, 2011.

[7] Z. Xin, and Y. Zhang, "Low carbon economy and low carbon city," Urban Study, vol. 4, pp. 98-102, 2008.

[8] E. H.K. Yung, and E. H.W. Chan, "Implementation challenges to the adaptive reuse of heritage buildings: towards the goals of sustainable, low carbon cities," Habitat International, vol. 36, no. 3, pp. 352-361, 2012.

[9] D. Scott, P. Paul, and S. Gössling, "Can tourism deliver its "aspirational" greenhouse gas emission reduction targets?," Journal of Sustainable Tourism, vol. 18, no. 3, pp. 393-408, 2010.

[10] K. F. Wee, "Energy consumption and carbon dioxide emission considerations in the urban planning process in Malaysia," pp. 1-30, 2008 .

Received: June 10, 2015

Revised: July 29, 2015

Accepted: August 15,2015

(C) Yingfa Yang; Licensee Bentham Open.

This is an open access article licensed under the terms of the (https://creativecommons.org/licenses/by/4.0/legalcode), which permits unrestricted, noncommercial use, distribution and reproduction in any medium, provided the work is properly cited. 